- Notes -

\title{
An X-ray Study of the Surfactant Gel Extraction Method Separation Mechanism and Its Application to Separate Nickel(II) from Copper(II) and as Ammine-Complexes Using the Anionic Surfactant SDS
}

\author{
Yoshiko MURAKAMI, ${ }^{1}$ Akihiro KAJII, ${ }^{1}$ Yoshiaki SASAKI, ${ }^{1}$ Koji NOZAKI, ${ }^{1}$ \\ Isamu FUJIWARA ${ }^{2}$ and Shoji TAGASHIRA ${ }^{1 \dagger}$ \\ ${ }^{1}$ Graduate School of Science and Engineering, Yamaguchi University, 1677-1 Yoshida, \\ Yamaguchi 753-8512, Japan, \\ ${ }^{2}$ Center for Waste Water Treatment, Science Research Center, Yamaguchi University, Yoshida, \\ Yamaguchi 753-8511, Japan
}

(Received December 14, 2009; Accepted February 3, 2010)

\begin{abstract}
A micellar solution of sodium dodecylsulfate (SDS) can separate into two phases due to a temperature change or the addition of salts. SDS plays the roles of a pairing-ion for ammine-complexes and of an extraction medium. The ion-pair extraction mechanism was investigated by SAXS and DSC measurements. This extraction was used for the separation of $\mathrm{Cu}(\mathrm{II})$ as a minor component from $\mathrm{Ni}(\mathrm{II})$ as a dominant component.
\end{abstract}

\section{Introduction}

Interest has been shown in the separation of metal ions by extraction and/or adsorption methods which use a surfactant and a polymer electrolyte of a solid or a liquid as the extraction medium. ${ }^{1-5} \mathrm{~A}$ micellar solution of an ionic surfactant can separate into two phases due to a temperature change or the addition of salts. One is a surfactant-depleted phase (aqueous phase) and the other is a surfactant-rich phase (surfactant phase). Based on this phase separation phenomenon, surfactant extraction techniques ${ }^{6-11}$ have great potential in industrial applications for removal of organic pollutants and recovery of heavy metals from waste water.

An anionic surfactant, SDS, which has low toxicity and is easily biodegraded, has been used for many kinds of metal extraction as the extraction medium. In our work, we also employed ammonia as the complexing agent for metal ions. Ammonia is an important and inexpensive industrial substance and has a large number of uses. Nickel(II), $\mathrm{Cu}(\mathrm{II})$ and $\mathrm{Zn}$ (II) ion formed ammine complexes in ammonia medium 
and are extracted into the SDS gel after ion-pair formation with the dodecylsulfate anion (DS ). ${ }^{11}$ In the extraction of ammine complexes, the extractability of metals reduced with lower metal concentration. This phenomenon did not occur in traditional extraction systems and was explained by the solubilisation of these ion-pairs with $\mathrm{DS}^{-}$and $\mathrm{M}\left(\mathrm{NH}_{3}\right)_{4}{ }^{2+}$, where $\mathrm{M}$ is a metal ion. In the SDS solution, which involves a solid SDS gel, the concentration of the monomer $\mathrm{DS}^{-}$in the aqueous phase is constant and the percent extraction $(E \%)$ is described using the ion-pair solubility product

$$
E(\%)=\left(1-\frac{K_{s p}}{\alpha[M]_{i n i}}\right) \times 100
$$

where $\alpha$ is the concentration of the SDS monomer in the aqueous phase, and $K_{\mathrm{sp}}$ is the solubility constant of the ion-pairs. ${ }^{11}$ We also confirmed that thiourea - complexes formed ion-pairs with the anionic surfactant, ${ }^{12}$ and that the chloro complexes also formed ion-pairs with the cationic surfactant. ${ }^{13-15}$

The purpose of the present study was to clarify the properties of the ion-pairs and to propose a new separation method for metal ions. We verified the formation of specific ion-pair crystals using X-ray diffraction and differential scanning calorimetry. Our hypothesis to explain the extraction mechanism was based on the formation of a new surfactant gel phase composed of metal ions and DS:

\section{Experimental}

\subsection{Reagents and chemicals}

The $1.00 \times 10^{-2} \mathrm{~mol} \mathrm{dm}^{-3}$ stock solutions of $\mathrm{Cu}(\mathrm{II}), \mathrm{Ni}(\mathrm{II})$ and $\mathrm{Pd}(\mathrm{II})$ were separately prepared by dissolving weighed amounts of copper(II) nitrate trihydrate (Kishida Chemicals, Tokyo) and nickel(II) nitrate hexahydrate (Wako Pure Chemicals, Tokyo) in $100 \mathrm{~cm}^{3}$ of $0.1 \mathrm{~mol} \mathrm{dm}^{-3}$ nitric acid, or palladium(II) chloride (Kanto Chemicals, Tokyo) in $100 \mathrm{~cm}^{3}$ of $0.1 \mathrm{~mol} \mathrm{dm}^{-3}$ hydrochloric acid. The anionic surfactant, 20\%(w/v) dodecyl sulfate, (SDS, Wako Pure Chemicals, Tokyo), was prepared by dissolving the reagent in deionized water without further purification. The salting-out reagent, $20 \%(\mathrm{w} / \mathrm{v})$ sodium chloride, (Kanto Chemicals, Tokyo), was prepared by dissolving it in deionized water. All other chemicals were of analytical grade and were dissolved in deionized water.

\subsection{Apparatus}

Metal concentrations were determined using a Varian Liberty Series II inductively coupled plasma atomic emission spectrometer (ICP-AES) or a Shimadzu AA-625-11 atomic absorption spectrophotometer. A Hitachi Himac CF7D2 centrifuge was used for phase separation. Small angle X-ray measurements (SAXS) were performed using a Brucker AXS DIP-220 powder X-ray diffractometer using copper K $\alpha$ radiation. Polarized light microscope images were obtained using a Nikon ECLIPSE E600.

\subsection{Procedure}

Isolation of the metal-surfactant ion-pair for SAX analysis

A solution containing 180 or $90 \mu \mathrm{mol}$ of $\mathrm{Cu}(\mathrm{II}), \mathrm{Ni}(\mathrm{II})$ or $\mathrm{Pd}(\mathrm{II})$ was transferred to a $10 \mathrm{~cm}^{3}$ centrifuge tube with a graduation line. After successively adding $0.27 \mathrm{~cm}^{3}$ of $28 \%$ ammonia and $0.5 \mathrm{~cm}^{3}$ of 
a 20\% (w/v) SDS (360 $\mu \mathrm{mol})$ solution, the final solution was shaken to form the ion-pair. Sodium chloride solution $\left(0.25 \mathrm{~cm}^{3}\right)$ was then added and the mixture was diluted to the mark with deionized water. After cooling the solution in an ice-water bath and centrifuging (5000 rpm, $10 \mathrm{~min}, 0^{\circ} \mathrm{C}$ ), the aqueous and SDS phases were separated. The aqueous phase was discarded, the SDS phase was subjected to gel structure measurement by small angle XRD (SAXS) or differential scanning calorimetry (DSC), respectively.

Separation of nickel(II) from copper(II)

A solution containing $2 \mu \mathrm{mol}$ of $\mathrm{Cu}(\mathrm{II})$ and $0.04 \mu \mathrm{mol}$ of $\mathrm{Ni}(\mathrm{II})$ was transferred to a $10 \mathrm{~cm}^{3}$ centrifuge tube with a graduation line. After successively adding $0.27 \mathrm{~cm}^{3}$ of ammonia and $0.5 \mathrm{~cm}^{3}$ of a $20 \%\left(\mathrm{w} / \mathrm{v}\right.$ ) SDS solution, the solution was shaken to form the ion-pair. The $0.25 \mathrm{~cm}^{3}$ sodium chloride solution was then added and the mixture was diluted to the mark with deionized water. After cooling the solution in an ice-water bath and centrifuging (5000 rpm, $10 \mathrm{~min}, 0^{\circ} \mathrm{C}$ ), the aqueous and SDS phases were separated. The aqueous phase was transferred to another tube and its metal concentration determined by ICP-AES in order to calculate the percent extraction of the metal ions.

\section{Results and Discussion}

SDS deposits as a gel-like solid from aqueous solution on adding a salting out reagent or cooling. Ammine complexes of $\mathrm{Co}(\mathrm{II}), \mathrm{Ni}(\mathrm{II})$ and $\mathrm{Pd}(\mathrm{II})$ are extracted into the SDS gel. ${ }^{11}$ We identified the phenomenon in which the extractability of $\mathrm{Pd}(\mathrm{II}), \mathrm{Ni}(\mathrm{II})$ and $\mathrm{Cu}(\mathrm{II})$ complexes into the SDS phase decreased at low metal concentrations, and the dependences of the metal concentrations on $E(\%)$ were explicable by $K_{\mathrm{sp}}$, respectively. To explain the mechanism of formation of these ion-pairs, the properties of the ion-pairs requires elucidation.

\subsection{Polarized light microscope image}

Figure 1 is a polarized light microscope image of the separated SDS phase containing ion pair of $\mathrm{Cu}(\mathrm{II})$ complex with $\mathrm{DS}^{-}$at room temperature (about $25^{\circ} \mathrm{C}$ ). A part of the SDS phase melted at this temperature and the polarized light disappeared. The liquefied part is the dark portion surrounded by white lines. The crystals of the $\left[\mathrm{Cu}\left(\mathrm{NH}_{3}\right)_{4}(\mathrm{DS})_{2}\right]$ ion-pairs did not liquefy and were identified by polarized light.

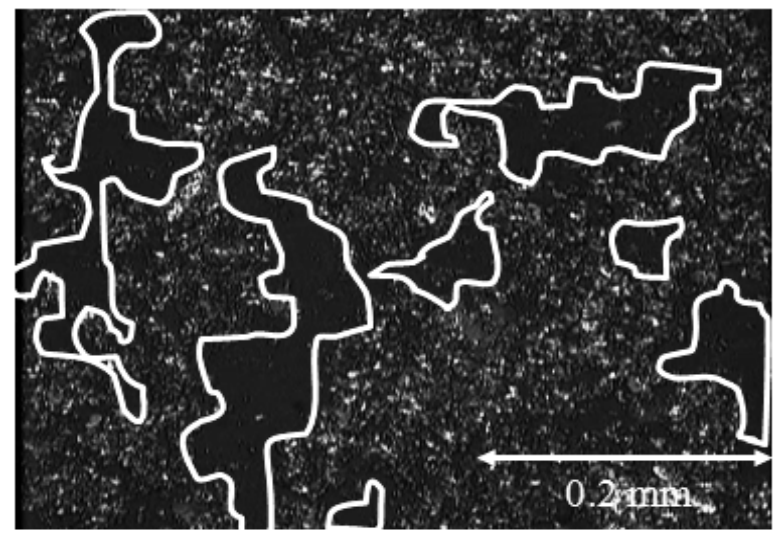

\subsection{Melting point measurement}

The melting point of the SDS gel containing $\mathrm{Cu}(\mathrm{II})$ ion, separated from the water phase by the

Fig. 1 Polarized light microscope image of the SDS phase. addition of $\mathrm{NaCl}$, was measured by DSC. As shown in Fig. 2, three endothermic peaks were observed at $0{ }^{\circ} \mathrm{C}, 20^{\circ} \mathrm{C}$, and $77^{\circ} \mathrm{C}$ representing ice melting, 
the SDS gel melting, and the $\left[\mathrm{Cu}\left(\mathrm{NH}_{3}\right)_{4}(\mathrm{DS})_{2}\right]$ ion-pair melting, respectively. These results suggest independent formation of the pure SDS and metal ion-pair gels.

\subsection{SAXS analysis}

The formation of the ion-pair in the SDS phase was verified using SAXS measurements. As the obtained SDS phase was a liquid at room temperature, therefore, the SAXS sample cell was cooled using liquid nitrogen vapor. It is already known that the SDS have lamellar structures. ${ }^{16,17}$ The SAXS pattern for the pure SDS phase, which contained SDS and water but no metal-ammine complex, also possessed one reflection peak at $3.06^{\circ}\left(d_{001}=2.88 \mathrm{~nm}\right.$, Fig.3a) exhibiting a lamellar structure. On the other hand, the SDS phase with a composition of $1: 2=\mathrm{Cu}(\mathrm{II})$ : SDS showed a reflection peak at $3.56^{\circ}\left(d_{001}=2.48 \mathrm{~nm}\right.$, Fig.3c). At a mole ratio of $1: 2$, all the SDS completely reacted with the $\mathrm{Cu}(\mathrm{II})$ ammine complex. This ion-pair, $\left[\mathrm{Cu}\left(\mathrm{NH}_{3}\right)_{4}(\mathrm{DS})_{2}\right]$, also showed a lamellar structure. There are two possible mechanisms for the formation of the ion-pair of the $\mathrm{Cu}(\mathrm{II})$ complex with $\mathrm{DS}^{-}$. One is the intercalation of $\left[\mathrm{Cu}\left(\mathrm{NH}_{3}\right)_{4}\right]^{2+}$ by ion-exchange with $\mathrm{Na}^{+}$in the hydrophilic layer of the SDS gel and SAXS will show only one reflection peak which shifts from low to high

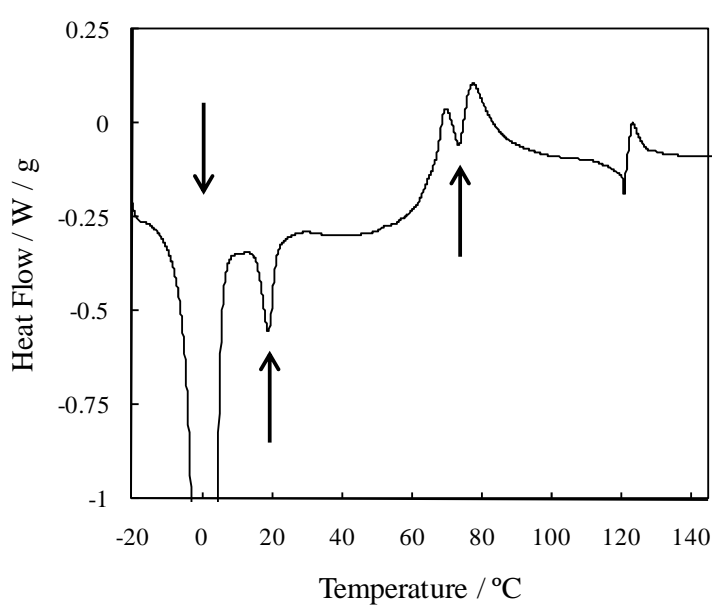

Fig. 2 The DSC curve for the SDS phase.

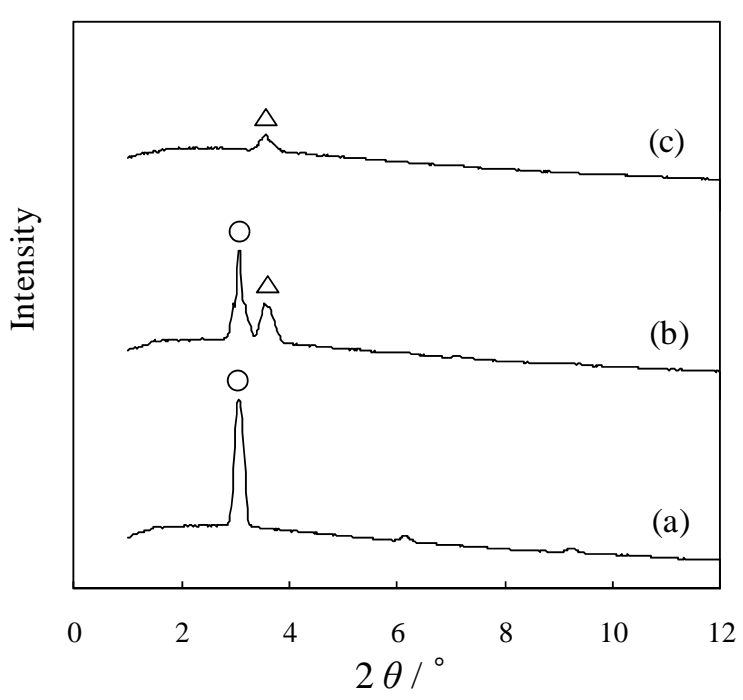

Fig. 3 SAXS patterns for (a) pure SDS, (b) SDS $+\mathrm{Cu}(\mathrm{II})$ ion-pair, (c) $\mathrm{Cu}(\mathrm{II})$ ion-pair.

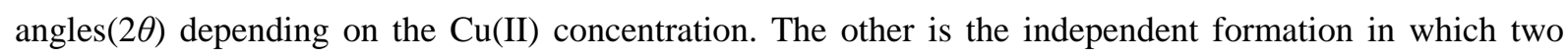
reflection peaks corresponding to pure SDS and the ion-pair $\left[\mathrm{Cu}\left(\mathrm{NH}_{3}\right)_{4}(\mathrm{DS})_{2}\right]$ will appear in the SAXS pattern. The phase in which the molar ratio was $1: 4=\mathrm{Cu}(\mathrm{II})$ : SDS gave two peaks at $3.06^{\circ}\left(d_{001}=2.88 \mathrm{~nm}\right)$ and $3.54^{\circ}\left(d_{001}=2.49 \mathrm{~nm}\right)$ corresponding to the pure SDS and the $\mathrm{Cu}$ (II) ion-pair (Fig.3b). The same results were obtained for $\mathrm{Ni}(\mathrm{II})$ and $\mathrm{Pd}(\mathrm{II})$ with basal spacings of $d_{001}=2.02$ and $2.95 \mathrm{~nm}$, respectively.

In Fig.4, the SAXS pattern of the SDS phase obtained from an aqueous solution containing $1 \times 10^{-4}$ mol dm${ }^{-3}$ of $\mathrm{Cu}(\mathrm{II})$ - and $1 \times 10^{-4} \mathrm{~mol} \mathrm{dm}^{-3} \mathrm{Ni}(\mathrm{II})-$ ammine complexes and excess SDS is shown together with those of pure SDS, $\left[\mathrm{Cu}\left(\mathrm{NH}_{3}\right)_{4}(\mathrm{DS})_{2}\right]$, and $\left[\mathrm{Ni}\left(\mathrm{NH}_{3}\right)_{4}(\mathrm{DS})_{2}\right]$. As shown in Fig.4, peaks at $3.06^{\circ}, 3.56^{\circ}$, and $4.38^{\circ}$ appeared corresponding to pure SDS, $\left[\mathrm{Cu}\left(\mathrm{NH}_{3}\right)_{4}(\mathrm{DS})_{2}\right]$ and $\left[\mathrm{Ni}\left(\mathrm{NH}_{3}\right)_{4}(\mathrm{DS})_{2}\right]$, respectively, at 
their original positions. It is concluded that the SDS phase consisted of pure $\mathrm{Cu}(\mathrm{II})$ ion-pair, $\mathrm{Ni}(\mathrm{II})$ ion-pair and pure SDS gel as shown in Fig.5. It is clear that these ion-pairs formed independently.

\subsection{Separation of $\mathrm{Cu}(\mathrm{II})-\mathrm{Ni}(\mathrm{II})$ mixture}

The separation of $\mathrm{Cu}(\mathrm{II})$ and $\mathrm{Ni}(\mathrm{II})$ was attempted using the present method of surfactant gel precipitation-extraction (SGE). If the SGE method can prevent the co-precipitation of existing metal ions, the major component will be removed from the minor component when the concentration is less than its solubility. The SGE method was carried out for a sample of $\mathrm{Cu}(\mathrm{II}): \mathrm{Ni}(\mathrm{II})=50: 1$. As described in a previous paper, ${ }^{11}$ the nickel(II)-ammine complex was not extracted at a concentration of $4.0 \times 10^{-6} \mathrm{~mol} \mathrm{dm}^{-3}$, whereas the copper(II)-ammine complex was extracted at a concentration of $2.0 \times 10^{-4} \mathrm{~mol} \mathrm{dm}^{-3}$. Nickel(II) was not extracted from the mixed solution of copper(II) and nickel(II) ions of each concentration as reported above under these conditions, therefore, co-precipitation or occlusion of nickel(II) ions was not observed. The percent extractions obtained for $\mathrm{Cu}$ and $\mathrm{Ni}$ were $98.3 \pm$ $0.7 \%$ and $-0.7 \pm 1.1 \%$ respectively based on three measurements.

Most of the conventional precipitation methods are accompanied by the co-precipitation of many metal ions and therefore lack selectivity. The present SGE method could separate the minor and major components and is regarded as a new separation method.

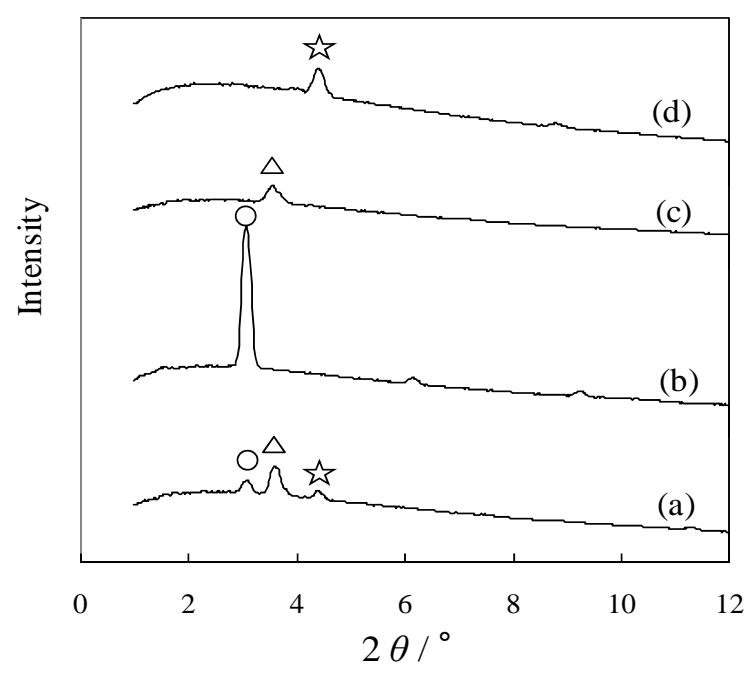

Fig.4 SAXS patterns for (a) SDS + $\mathrm{Cu}(\mathrm{II})$ ion-pair + Ni(II) ion-pair, (b) SDS, (c) Cu(II) ion-pair, (d) Ni(II) ion-pair.

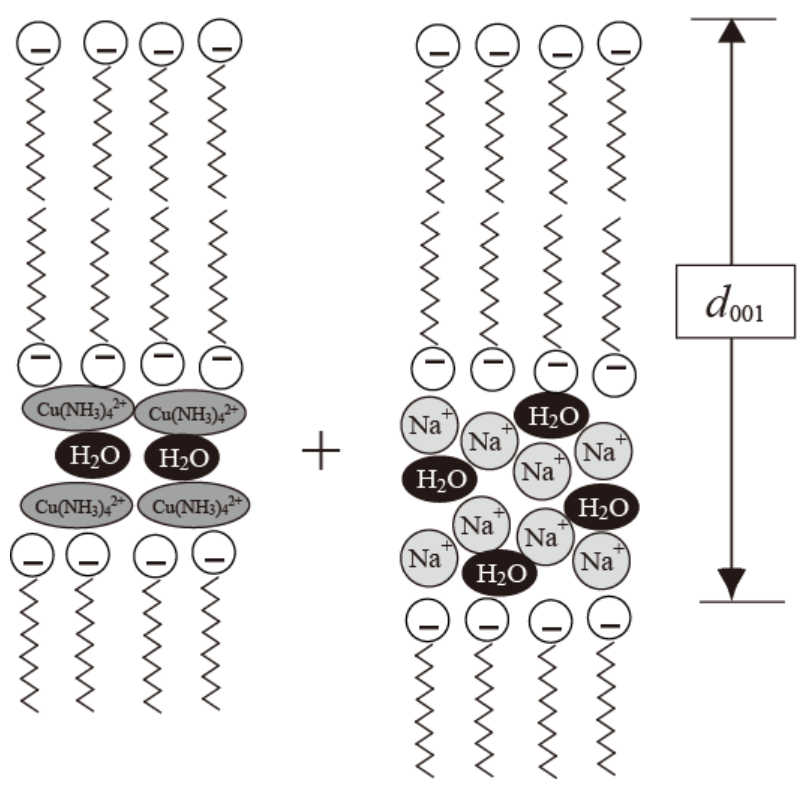

Fig.5 The schematic lamellar structures of the SDS phase consisting of $\mathrm{Cu}(\mathrm{II})$ ion-pairs and pure SDS gel.

\section{Acknowledgements}

The present work was partially supported by a Grant-in-Aid for Scientific Research (No.18510075) from the Japan Society for Promotion of Science (JSPS). 


\section{References}

1) J. F. Scamehorn, J. H. Harwell, Surfactant-Based Separations, Science and Technology, 2000, ACS, Washington.

2) A. Paulenova, P. Rajec, M. Jezikova, J. Radioanal. Nucl. Chem., 228, 119 (1998).

3) B. R. Fillipi, J. F. Scamehorn, R. R. Taylpr, R. D. Christian, Sep. Sci. Technol., 32, 2401 (1997).

4) C. Matsubara, Bunseki, 60 (1999).

5) D. L. Giokas, G. Z. Tsogas, A. G. Vlessides, M. I. Karayannis, Anal. Chem., 76, 1302 (2004).

6) S. Tagashira, T. Nakai, Y. Murakami, Y. Sasaki, J. Environ. Chem., 11, 855 (2001).

7) C. Tondre, ACS Symposium Series, 740, 139 (2000).

8) S. Tagashira, Y. Murakami, M. Yano, Y. Sasaki, Bull. Chem. Soc, Jpn., 71, 2137 (1998).

9) M. Hebrant, A. Bouraine, A. Brembilla, P. Lochon, C. Tondre, Colloid Polym. Sci., 273, 598 (1995).

10) Y. Murakami, K. Hiraiwa, Y. Sasaki, I. Fujiwara, S. Tagashira, Anal. Sci., 23, 1147 (2007).

11) T. Nakai, Y. Murakami, Y. Sasaki, S. Tagashira, Talanta, 66, 45 (2005).

12) S. Tagashira, S. Kimoto, K. Nozaki, Y. Murakami, Anal. Sci., 25,723 (2009).

13) Y. Murakami, K. Hiraiwa, Y. Sasaki, I. Fujiwara, S. Tagashira, Anal. Sci., 23, 1147 (2007).

14) Y. Murakami, Y. Dobashi, Y. Sasaki, I. Fujiwara, N. Abe, S. Tagashira, Solv. Extr. Res. Dev., Jap., 15, 121 (2008).

15) Y. Dobashi, Y. Murakami, I. Fujiwara, N. Abe, S. Tagashira, Solv. Extr. Res. Dev., Jap., 16, 133 (2009).

16) H. Luo, L. Sun. Y. Lu, Y. Yan, Langmuir, 20, 10218 (2004).

17) Y. Tan, E. M. P. Steinmiller, K-S. Choi, Langmuir, 21, 9618 (2005). 